\title{
Two efficient modifications of AZPRP conjugate gradient method with sufficient descent property
}

\author{
Zabidin Salleh $^{1 *}$ (D) Adel Almarashi ${ }^{2}$ and Ahmad Alhawarat ${ }^{1}$
}

"Correspondence:
zabidin@umt.edu.my
'Department of Mathematics,
Faculty of Ocean Engineering
Technology and Informatics,
Universiti Malaysia Terengganu,
21030 Kuala Nerus, Terengganu,
Malaysia
Full list of author information is
available at the end of the article

\begin{abstract}
The conjugate gradient method can be applied in many fields, such as neural networks, image restoration, machine learning, deep learning, and many others. Polak-Ribiere-Polyak and Hestenses-Stiefel conjugate gradient methods are considered as the most efficient methods to solve nonlinear optimization problems. However, both methods cannot satisfy the descent property or global convergence property for general nonlinear functions. In this paper, we present two new modifications of the PRP method with restart conditions. The proposed conjugate gradient methods satisfy the global convergence property and descent property for general nonlinear functions. The numerical results show that the new modifications are more efficient than recent CG methods in terms of number of iterations, number of function evaluations, number of gradient evaluations, and CPU time.
\end{abstract}

MSC: 49M37;65K05; 90C3

Keywords: Conjugate gradient method; Strong Wolfe-Powell line search; Polak-Ribiere-Polyak method; Global convergence

\section{Introduction}

We consider the following form for the unconstrained optimization problem:

$$
\min \left\{f(x) \mid x \in R^{n}\right\}
$$

where $f: R^{n} \rightarrow R$ is a continuously differentiable function and its gradient is denoted by $g(x)=\nabla f(x)$. To solve (1.1) using the CG method, we use the following iterative method starting from the initial point $x_{0} \in R^{n}$. Then

$$
x_{k+1}=x_{k}+\alpha_{k} d_{k}, \quad k=0,1,2, \ldots,
$$

(c) The Author(s) 2022. This article is licensed under a Creative Commons Attribution 4.0 International License, which permits use, sharing, adaptation, distribution and reproduction in any medium or format, as long as you give appropriate credit to the original author(s) and the source, provide a link to the Creative Commons licence, and indicate if changes were made. The images or other third party material in this article are included in the article's Creative Commons licence, unless indicated otherwise in a credit line to the material. If material is not included in the article's Creative Commons licence and your intended use is not permitted by statutory regulation or exceeds the permitted use, you will need to obtain permission directly from the copyright holder. To view a copy of this licence, visit http://creativecommons.org/licenses/by/4.0/. 
where $\alpha_{k}>0$ is the step size obtained by some line search. The search direction $d_{k}$ is defined by

$$
d_{k}= \begin{cases}-g_{k}, & k=0, \\ -g_{k}+\beta_{k} d_{k-1}, & k \geq 1,\end{cases}
$$

where $g_{k}=g\left(x_{k}\right)$ and $\beta_{k}$ is known as the conjugate gradient method. To obtain the steplength $\alpha_{k}$, we have the following two line searches:

1. Exact line search

$$
f\left(x_{k}+\alpha_{k} d_{k}\right)=\min f\left(x_{k}+\alpha d_{k}\right), \quad \alpha \geq 0 .
$$

However, (1.4) is computationally expensive if the function has many local minima.

2. Inexact line search

To overcome the cost of using exact line search and obtain steps that are neither too long nor too short, we usually use inexact line search, in particular weak Wolfe-Powell (WWP) line search $[1,2]$ given as follows:

$$
\begin{aligned}
& f\left(x_{k}+\alpha_{k} d_{k}\right) \leq f\left(x_{k}\right)+\delta \alpha_{k} g_{k}^{T} d_{k}, \\
& g\left(x_{k}+\alpha_{k} d_{k}\right)^{T} d_{k} \geq \sigma g_{k}^{T} d_{k} .
\end{aligned}
$$

Another, strong, version of Wolfe-Powell (SWP) line search is given by (1.5) and

$$
\left|g\left(x_{k}+\alpha_{k} d_{k}\right)^{T} d_{k}\right| \leq \sigma\left|g_{k}^{T} d_{k}\right|
$$

where $0<\delta<\sigma<1$.

The descent condition (downhill condition) plays an important role in the CG method, where the equation of the descent condition is given as follows:

$$
g_{k}^{T} d_{k}<0
$$

Albaali [3] extended (1.8) to the following form:

$$
g_{k}^{T} d_{k} \leq-c\left\|g_{k}\right\|^{2}, \quad k \geq 0 \text { and } c>0,
$$

called the sufficient descent condition.

The steepest descent method is the simplest of the gradient methods for optimization functions in $n$ variables. From a current trial point $x_{1}$, for a function $f(x)$, one expects to find a vector close to a minimum by moving away from $x_{1}$ along the direction which causes $f(x)$ to decrease rapidly, i.e., $f\left(x_{1}\right)>f\left(x_{2}\right)>f\left(x_{3}\right)>\cdots$. This direction of steepest descent is given by the negative gradient, $-g_{k}$. Using contour lines, the minimum point of a function is obtained with two variables. For example, Fig. 1 shows contour lines for Booth function in two dimensions.

As we see in Fig. 2, the gradient $f^{\prime}(x)$ is orthogonal with the contour lines, and for every $x$, the gradient point in the direction of the steepest increases $f(x)$. In Fig. 2, the gradient, 


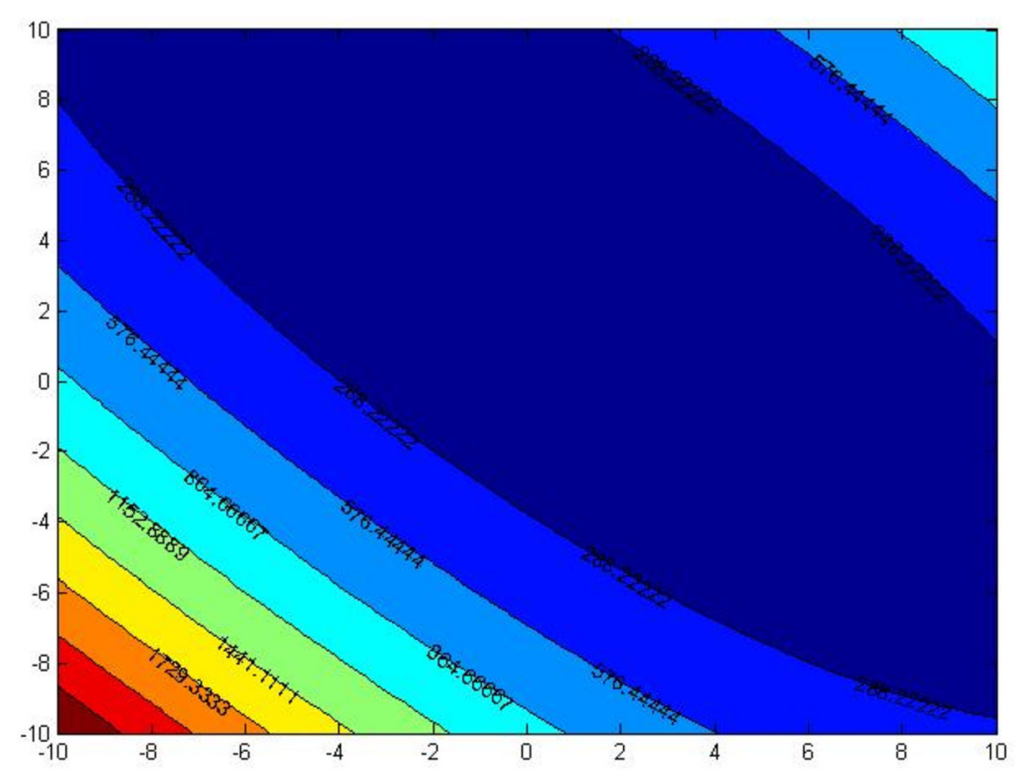

Figure 1 Contour lines for Booth function

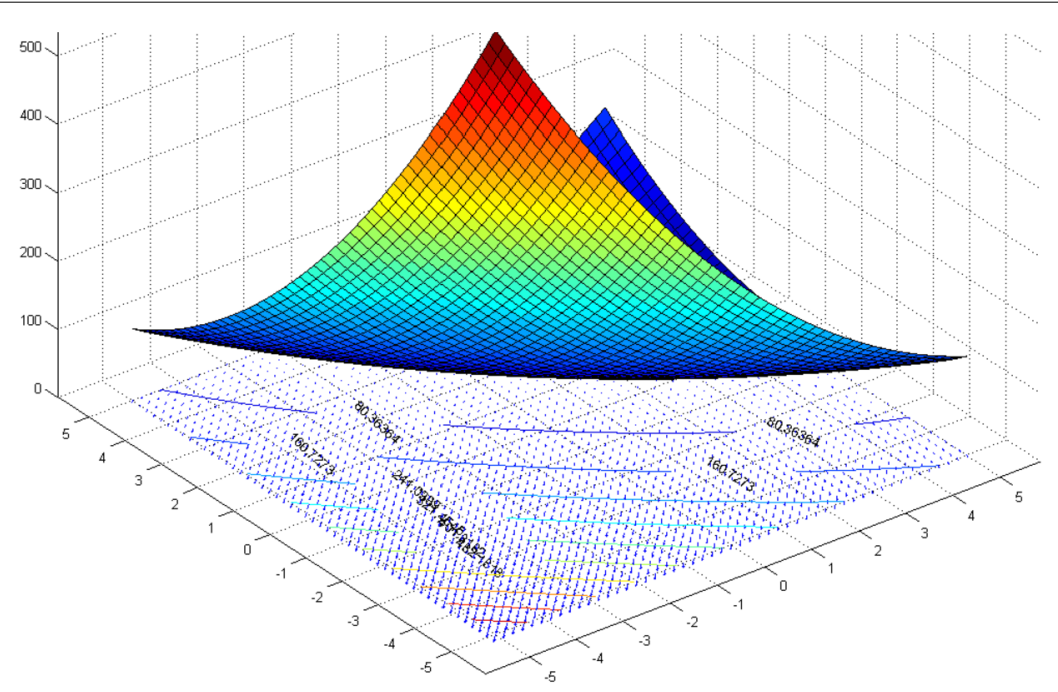

Figure 2 The graph of Booth function with contour lines and its gradients

contours, and Booth function are plotted, which clearly portrays the function's minimum using the function or contour line graph. Despite the steepest descent method robustness, it is not efficient due to CPU time for large-dimensional functions. Thus, using the CG method will avoid the orthogonality between the $\nabla f$ and the search direction. Figure 3 shows the angle between the $\nabla f$ and $d_{k}$ using the CG method.

$$
\cos \left(\theta_{k}\right)=\left(-\frac{d_{k}^{T} g_{k}}{\left\|d_{k}\right\|\left\|g_{k}\right\|}\right)
$$




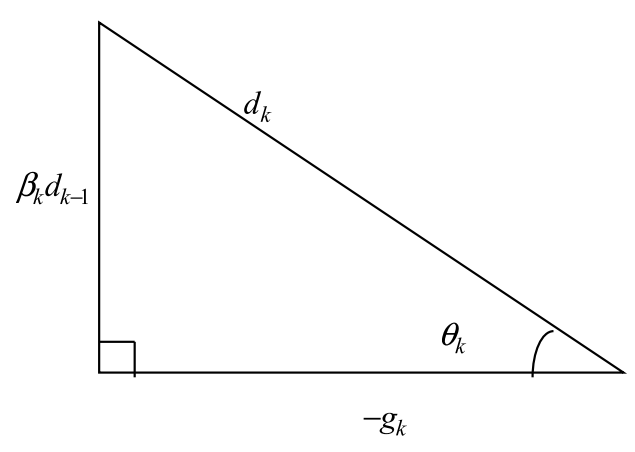

Figure 3 The angle between the negative gradient and the search direction

The most famous classical formulas of CG methods are Hestenses-Stiefel (HS) [3], PolakRibiere-Polyak (PRP) [4], Liu and Storey (LS) [5], Fletcher-Reeves (FR) [6], Fletcher (CD) [7], Dai and Yuan (DY) [8], given as follows:

$$
\begin{array}{lll}
\beta_{k}^{\mathrm{HS}}=\frac{g_{k}^{T} y_{k-1}}{d_{k-1}^{T} y_{k-1}}, & \beta_{k}^{\mathrm{PRP}}=\frac{g_{k}^{T} y_{k-1}}{\left\|g_{k-1}\right\|^{2}}, & \beta_{k}^{\mathrm{LS}}=-\frac{g_{k}^{T} y_{k-1}}{d_{k-1}^{T} g_{k-1}}, \\
\beta_{k}^{\mathrm{FR}}=\frac{\left\|g_{k}\right\|^{2}}{\left\|g_{k-1}\right\|^{2}}, & \beta_{k}^{\mathrm{CD}}=-\frac{\left\|g_{k}\right\|^{2}}{d_{k-1}^{T} g_{k-1}}, & \beta_{k}^{\mathrm{DY}}=\frac{\left\|g_{k}\right\|^{2}}{d_{k-1}^{T} g_{k-1}},
\end{array}
$$

where $y_{k-1}=g_{k}-g_{k-1}$.

These methods are similar if we use exact line search and a function satisfying quadratic line search condition since $g_{k}^{T} d_{k-1}=0$, which implies $g_{k}^{T} d_{k}=-\left\|g_{k}\right\|^{2}$ using (1.3). In addition, if the function is quadratic, then $g_{k}^{T} g_{k-1}=0$.

The global convergence properties were studied by Zoutendijk [9] and Al-Baali [10]. The global convergence of the PRP method for a convex objective function under exact line search was proved by Polak and Ribere in [4]. Later, Powell [11] gave a counterexample showing a nonconvex function, in which PRP and HS can cycle infinitely without getting a solution. Powell emphasized the importance to achieve the global convergence of PRP and HS method, which should not be negative. Moreover, Gilbert and Nocedal [12] proved that nonnegative PRP, i.e., with $\beta_{k}=\max \left\{\beta_{k}^{\text {PRP }}, 0\right\}$, is globally convergent under complicated line searches.

Since the function is quadratic, i.e., the step size is obtained by exact line search (1.4), the CG method satisfies the conjugacy condition, i.e., $d_{i}^{T} H d_{j}^{T}=0, \forall i \neq j$. Using the mean value theorem and exact line search with equation (1.3), we can obtain $\beta_{k}^{\text {HS }}$. From the quasiNewton method, BFGS method, the limited memory (LBFGS) method, and equation (1.3), Dai and Liao [13] proposed the following conjugacy condition:

$$
d_{k}^{T} y_{k-1}=-\operatorname{tg}_{k}^{T} s_{k-1}
$$

where $s_{k-1}=x_{k}-x_{k-1}$, and $t \geq 0$. In the case of $t=0$, equation (1.10) becomes the classical conjugacy condition. By using (1.3) and (1.10), [13] proposed the following CG formula:

$$
\beta_{k}^{\mathrm{DL}}=\frac{g_{k}^{T} y_{k-1}}{d_{k-1}^{T} y_{k-1}}-t \frac{g_{k}^{T} s_{k-1}}{d_{k-1}^{T} y_{k-1}} .
$$


However, $\beta_{k}^{\mathrm{DL}}$ faces the same problem as $\beta_{k}^{\mathrm{PRP}}$ and $\beta_{k}^{\mathrm{HS}}$, i.e., $\beta_{k}^{\mathrm{DL}}$ is not nonnegative in general. Thus, [13] replaced equation (1.11) by

$$
\beta_{k}^{\mathrm{DL}+}=\max \left\{\beta_{k}^{\mathrm{HS}}, 0\right\}-t \frac{g_{k}^{T} s_{k-1}}{d_{k-1}^{T} y_{k-1}} .
$$

Moreover, Hager and Zhang [14, 15] presented a modified CG parameter that satisfies the descent property for any inexact line search with $g_{k}^{T} d_{k} \leq-(7 / 8)\left\|g_{k}\right\|^{2}$. This new version of the CG method is globally convergent whenever the line search satisfies the (WP) line search requirement. This formula is given as follows:

$$
\beta_{k}^{\mathrm{HZ}}=\max \left\{\beta_{k}^{N}, \eta_{k}\right\}
$$

where $\beta_{k}^{N}=\frac{1}{d_{k}^{T} y_{k}}\left(y_{k}-2 d_{k} \frac{\left\|y_{k}\right\|^{2}}{d_{k}^{T} y_{k}}\right)^{T} g_{k}, \eta_{k}=-\frac{1}{\left\|d_{k}\right\| \min \left\{\eta,\left\|g_{k}\right\|\right\}}$, and $\eta>0$ is a constant.

Note that if $t=2 \frac{\left\|y_{k}\right\|^{2}}{s_{k}^{T} y_{k}}$, then $\beta_{k}^{N}=\beta_{k}^{\text {DY }}$.

In 2006, Wei et al. [16] gave a new positive CG method, which is quite similar to the original PRP method, which has global convergence under exact and inexact line search, that is,

$$
\beta_{k}^{\mathrm{WYL}}=\frac{g_{k}^{T}\left(g_{k}-\frac{\left\|g_{k}\right\|}{\left\|g_{k-1}\right\|} g_{k-1}\right)}{\left\|g_{k-1}\right\|^{2}},
$$

where $y_{k-1}=g_{k}-g_{k-1}$. From the WYL method, many modifications appeared, such as the following [17]:

$$
\beta_{k}^{\mathrm{DPRP}}=\frac{\left\|g_{k}\right\|^{2}-\frac{\left\|g_{k}\right\|}{\left\|g_{k-1}\right\|}\left|g_{k} g_{k-1}\right|}{m\left|g_{k}^{T} d_{k-1}\right|+\left\|g_{k-1}\right\|^{2}}, \quad m \geq 1[11]
$$

and

$$
\beta_{k}^{\text {DHS }}=\frac{\left\|g_{k}\right\|^{2}-\frac{\left\|g_{k}\right\|}{\left\|g_{k-1}\right\|} g_{k}^{T} g_{k-1}}{m\left|g_{k}^{T} d_{k-1}\right|+d_{k-1}^{T} y_{k-1}}, \quad \text { where } m>1 .
$$

Alhawarat et al. [18] constructed the following CG method with a new restart criterion as follows:

$$
\beta_{k}^{\mathrm{AZPRP}}= \begin{cases}\frac{\left\|g_{k}\right\|^{2}-\mu_{k} \cdot\left|g_{k}^{T} g_{k-1}\right|}{\left\|g_{k-1}\right\|^{2}}, & \left\|g_{k}\right\|^{2}>\mu_{k} \cdot\left|g_{k}^{T} g_{k-1}\right| \\ 0, & \text { otherwise }\end{cases}
$$

where $\mu_{k}=\frac{\left\|s_{k}\right\|}{\left\|y_{k}\right\|}, s_{k}=x_{k}-x_{k-1}, y_{k}=g_{k}-g_{k-1}$, and $\|\cdot\|$ denotes the Euclidean norm.

Besides, Kaelo et al. [19] proposed the following CG formula:

$$
\beta_{k}^{\text {PKT }}= \begin{cases}\frac{\left\|g_{k}\right\|^{2}-g_{k}^{T} g_{k-1}}{\max \left\{d_{k-1}^{T} y_{k-1},-g_{k-1}^{T} d_{k-1}\right\}}, & \text { if } 0<g_{k}^{T} g_{k-1}<\left\|g_{k}\right\|^{2}, \\ \frac{\left\|g_{k}\right\|^{2}}{\max \left\{d_{k-1}^{T} y_{k-1},-g_{k-1}^{T} d_{k-1}\right\}}, & \text { otherwise. }\end{cases}
$$




\section{Motivation and the new restarted formula}

To improve the efficiency of $\beta_{k}^{\text {AZPRP }}$ in terms of function evaluation, gradient evaluation, number of iterations, and CPU time, we construct two new CG methods based on $\beta_{k}^{\text {AZPRP }}$, $\beta_{k}^{\text {DPRP }}$, and $\beta_{k}^{\text {DHS }}$ as follows:

$$
\beta_{k}^{A 1}= \begin{cases}\frac{\left\|g_{k}\right\|^{2}-\mu_{k}\left|g_{k}^{T} g_{k-1}\right|}{m\left|g_{k}^{T} d_{k-1}\right|+\left\|g_{k-1}\right\|^{2}}, & \text { if }\left\|g_{k}\right\|^{2}>\mu_{k}\left|g_{k}^{T} g_{k-1}\right|, \\ -\mu_{k} \frac{g_{k}^{T} s_{k-1}}{d_{k-1}^{T} y_{k-1}}, & \text { otherwise, }\end{cases}
$$

where

$$
\mu_{k}=\frac{\left\|s_{k-1}\right\|}{\left\|y_{k-1}\right\|} .
$$

The second modification is given as follows:

$$
\beta_{k}^{A 2}= \begin{cases}\frac{\left\|g_{k}\right\|^{2}-\mu_{k}\left|g_{k}^{T} g_{k-1}\right|}{m\left|g_{k}^{T} d_{k-1}\right|+d_{k-1}^{T} y_{k-1}}, & \text { if }\left\|g_{k}\right\|^{2}>\mu_{k}\left|g_{k}^{T} g_{k-1}\right|, \\ -\mu_{k} \frac{g_{k}^{T} s_{k-1}^{T}}{d_{k-1}^{T} y_{k-1}}, & \text { otherwise. }\end{cases}
$$

\section{Algorithm 2.1}

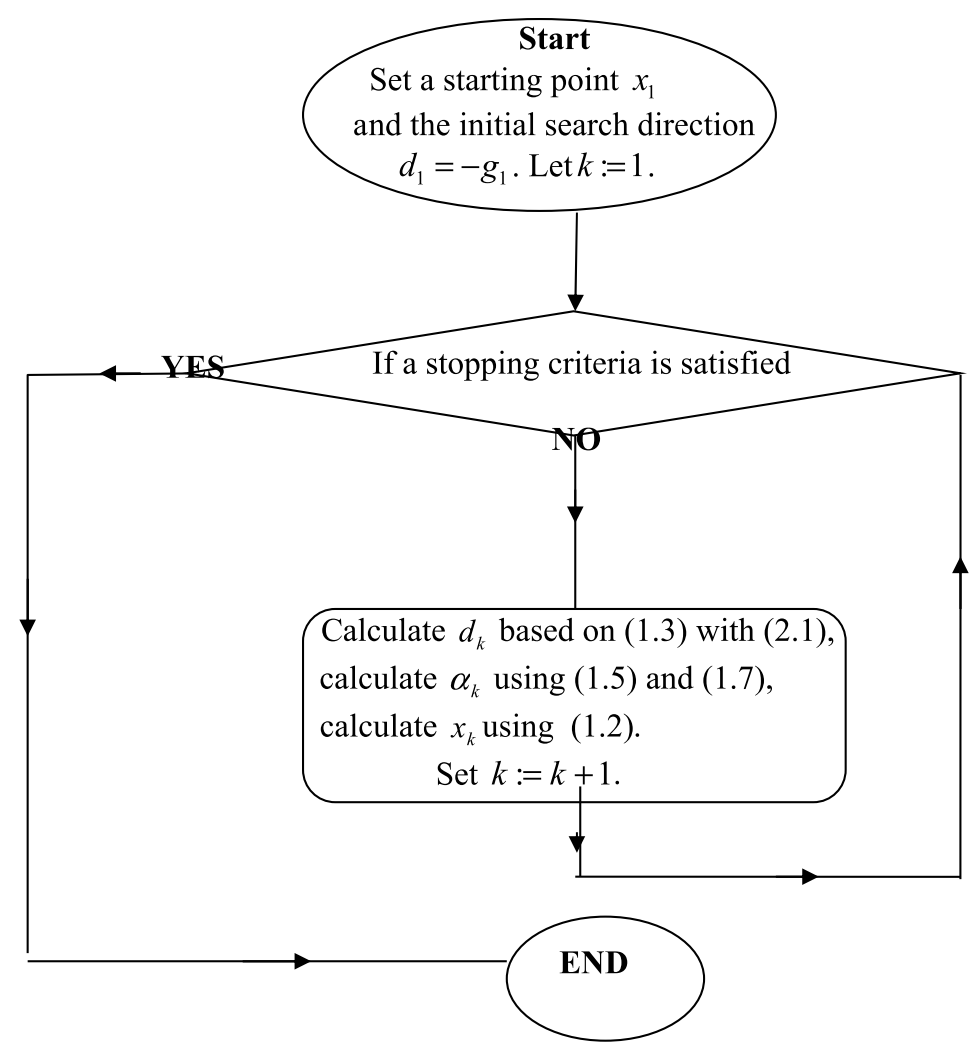

\section{The global convergence properties}

\section{Assumption 1}

I. $f(x)$ is bounded from below on the level set $\Omega=\left\{x \in R^{n}: f(x) \leq f\left(x_{1}\right)\right\}$, where $x_{1}$ is the starting point. 
II. In some neighborhood $N$ of $\Omega, f$ is continuous and differentiable, and its gradient is Lipchitz continuous. That is, for any $x, y \in N$, there exists a constant $L>0$ such that

$$
\|g(x)-g(y)\| \leq L\|x-y\|
$$

The following is considered one of the most important lemmas used to prove the global convergence properties. For more details, the reader can refer to [9].

Lemma 3.1 Suppose Assumption 1 holds. Considering the CG method of the form (1.3), where the search direction satisfies the sufficient descent condition and $\alpha_{k}$ exists by standard WWP line search, we have

$$
\sum_{k=0}^{\infty} \frac{\left(g_{k}^{T} d_{k}\right)^{2}}{\left\|d_{k}\right\|^{2}}<\infty
$$

where (3.1) is known as the Zoutendijk condition. Inequality (3.1) also holds for the exact line search, the Armijo-Goldstein line search, and the SWP line search.

Substituting (1.9) into (3.1) yields

$$
\sum_{k=0}^{\infty} \frac{\left\|g_{k}\right\|^{4}}{\left\|d_{k}\right\|^{2}}<\infty
$$

Gilbert and Nocedal [11] presented an important theorem to find the global convergence of nonnegative PRP and nonnegative methods summarized by Theorem 3.3. Furthermore, they presented a nice property, called Property*, as follows:

Property* Consider a method of the form (1.1) and (1.2), and suppose $0<\gamma \leq\left\|g_{k}\right\| \leq \bar{\gamma}$. We say that the method possesses Property* if there exist constant $b>1$ and $\lambda>0$ such that for all $k \geq 1$, we get $\left|\beta_{k}\right| \leq b$, and if $\left\|x_{k}-x_{k-1}\right\| \leq \lambda$, then

$$
\left|\beta_{k}\right| \leq \frac{1}{2 b}
$$

The following theorem plays a crucial role in the CG method given in [11].

Theorem 3.1 Considering any CG method of the form (1.2) and (1.3), suppose the following conditions hold:

I. $\beta_{k}>0$.

II. The sufficient descent condition is satisfied.

III. The Zoutendijk condition holds.

IV. Property" is true.

V. Assumption 1 is satisfied.

Then, the iterates are globally convergent, i.e., $\lim _{k \rightarrow \infty}\left\|g_{k}\right\|=0$.

\subsection{The global convergence properties of $\beta_{k}^{A 1}$}

Theorem 3.2 Suppose that Assumption 1 holds. Then, by considering the CG method of the form (1.2), (1.3), and (2.1), where $\alpha_{k}$ is computed by (1.5) and (1.6) and the sufficient 
descent condition holds, we multiply (1.2) by $g_{k}^{T}$, which yields

$$
\begin{aligned}
g_{k} d_{k} & =-\left\|g_{k}\right\|^{2}+\frac{\left\|g_{k}\right\|^{2}-\mu_{k}\left|g_{k}^{T} g_{k-1}\right|}{m\left|g_{k}^{T} d_{k-1}\right|+\left\|g_{k-1}\right\|^{2}} g_{k}^{T} d_{k-1} \\
& \leq-\left\|g_{k}\right\|^{2}+\frac{\left\|g_{k}\right\|^{2}}{m\left|g_{k}^{T} d_{k-1}\right|+\left\|g_{k-1}\right\|^{2}}\left|g_{k}^{T} d_{k-1}\right| \\
& \leq-\left\|g_{k}\right\|^{2}+\frac{\left\|g_{k}\right\|^{2}}{m\left|g_{k}^{T} d_{k-1}\right|}\left|g_{k}^{T} d_{k-1}\right| \\
& \leq-\left\|g_{k}\right\|^{2}+\frac{\left\|g_{k}\right\|^{2}}{m\left|g_{k}^{T} d_{k-1}\right|}\left|g_{k}^{T} d_{k-1}\right| \\
& \leq\left\|g_{k}\right\|^{2}\left(-1+\frac{1}{m}\right) .
\end{aligned}
$$

Theorem 3.3 Suppose that Assumption 1 holds. Consider the CG method of the form (1.2), (1.3), and (2.3), where $\alpha_{k}$ is computed by (1.5) and (1.6), then $\beta_{k}^{A 1}$ satisfies Property*.

Proof Let $\lambda=\frac{\gamma^{2}}{2 L(L+1) \lambda \bar{\gamma} b}$ and

$$
\beta_{k}^{A 1}=\frac{\left\|g_{k}\right\|^{2}-\mu_{k}\left|g_{k}^{T} g_{k-1}\right|}{m\left|g_{k}^{T} d_{k-1}\right|+\left\|g_{k-1}\right\|^{2}} \leq \frac{\left\|g_{k}\right\|^{2}+\left|g_{k}^{T} g_{k-1}\right|}{\left\|g_{k-1}\right\|^{2}} \leq \frac{\left\|g_{k}\right\|\left(\left\|g_{k}\right\|+\left\|g_{k-1}\right\|\right)}{\left\|g_{k-1}\right\|^{2}} \leq \frac{2 \bar{\gamma}^{2}}{\gamma^{2}}=b>1 .
$$

To show that $\beta_{k}^{A 1} \leq \frac{1}{2 b}$, we have the following two cases:

Case 1: $\mu_{k}>1$

$$
\begin{aligned}
\beta_{k}^{A 1} & =\frac{\left\|g_{k}\right\|^{2}-\mu_{k}\left|g_{k}^{T} g_{k-1}\right|}{m\left|g_{k}^{T} d_{k-1}\right|+\left\|g_{k-1}\right\|^{2}} \leq \frac{\left\|g_{k}\right\|^{2}-\left|g_{k}^{T} g_{k-1}\right|}{\left\|g_{k-1}\right\|^{2}} \\
& \leq \frac{\left\|g_{k}\right\|\left\|g_{k}-g_{k-1}\right\|}{\left\|g_{k-1}\right\|^{2}} \leq \frac{L \lambda \bar{\gamma}}{\gamma^{2}} .
\end{aligned}
$$

Case 2: $\mu_{k}<1$

To satisfy Property* for $\beta_{k}^{A 1}$ with $\mu_{k}<1$, we need the following inequality:

$$
\left\|w_{k}\right\|+\left\|v_{k}\right\| \leq L\left\|w_{k}+v_{k}\right\|,
$$

where $w_{k}=g_{k}-\frac{1}{L} g_{k-1}$, and $v_{k}=\frac{1}{L} g_{k}-g_{k-1}$, which yields

$$
\begin{aligned}
\left|\beta_{k}^{A 1}\right| & \leq\left|\frac{\left\|g_{k}\right\|^{2}-\mu_{k}\left|g_{k}^{T} g_{k-1}\right|}{m\left|g_{k}^{T} d_{k-1}\right|+\left\|g_{k-1}\right\|^{2}}\right| \leq\left|\frac{\left\|g_{k}\right\|^{2}-\frac{1}{L}\left|g_{k}^{T} g_{k-1}\right|}{\left\|g_{k-1}\right\|^{2}}\right| \\
& \leq \frac{\left\|g_{k}\right\|\left\|g_{k}-\frac{1}{L} g_{k-1}\right\|}{\left\|g_{k-1}\right\|^{2}} .
\end{aligned}
$$

Using (3.3), we obtain

$$
\begin{aligned}
& \left\|g_{k}-\frac{1}{L} g_{k-1}\right\| \leq L\left\|g_{k}-\frac{1}{L} g_{k-1}+\frac{1}{L} g_{k}-g_{k-1}\right\| \leq(L+1)\left\|g_{k}-g_{k-1}\right\|, \\
& \left|\beta_{k}^{A 1}\right| \leq \frac{(L+1)\left\|g_{k}\right\|\left\|g_{k}-g_{k-1}\right\|}{\left\|g_{k-1}\right\|^{2}} \leq L \frac{(L+1) \lambda \bar{\gamma}}{\gamma^{2}} .
\end{aligned}
$$


Thus, in all cases

$$
\left|\beta_{k}^{A 1}\right| \leq \frac{L \lambda \bar{\gamma}}{\gamma^{2}} \leq \frac{L(L+1) \lambda \bar{\gamma}}{\gamma^{2}} \leq \frac{1}{2 b}
$$

The proof is completed.

Theorem 3.4 Suppose that Assumption 1 holds. Consider the CG method of the form (1.2), (1.3), and (2.3), where $\alpha_{k}$ is computed by (1.5) and (1.6), then $\lim _{k \rightarrow \infty}\left\|g_{k}\right\|=0$.

Proof We will apply Theorem 3.1. Note that the following properties hold for $\beta_{k}^{A 1}$ :

i. $\beta_{k}^{A 1}>0$.

ii. $\beta_{k}^{A 1}$ satisfies Property* using Theorem 3.3.

iii. $\beta_{k}^{A 1}$ satisfies the descent property using Theorem 3.2.

iv. Assumption 1 holds.

Thus, all properties in Theorem 3.1 are satisfied, which leads to $\lim _{k \rightarrow \infty}\left\|g_{k}\right\|=0$.

\subsection{The global convergence properties of $\beta_{k}^{A 2}$}

Theorem 3.5 Suppose Assumption 1 holds. Consider the CG method of the form (1.2), (1.3), and (2.3), where $\alpha_{k}$ is computed by (1.5) and (1.6), and where the sufficient descent condition holds for $\beta_{k}^{A 2}$. Since $d_{k-1}^{T} y_{k-1} \geq 0$, we obtain

$$
\begin{aligned}
g_{k} d_{k} & =-\left\|g_{k}\right\|^{2}+\frac{\left\|g_{k}\right\|^{2}-\mu_{k}\left|g_{k}^{T} g_{k-1}\right|}{m\left|g_{k}^{T} d_{k-1}\right|+d_{k-1}^{T} y_{k-1}} g_{k}^{T} d_{k-1} \\
& \leq-\left\|g_{k}\right\|^{2}+\frac{\left\|g_{k}\right\|^{2}}{m\left|g_{k}^{T} d_{k-1}\right|}\left|g_{k}^{T} d_{k-1}\right| \\
& \leq-\left\|g_{k}\right\|^{2}+\frac{\left\|g_{k}\right\|^{2}}{m\left|g_{k}^{T} d_{k-1}\right|}\left|g_{k}^{T} d_{k-1}\right| \\
& \leq\left\|g_{k}\right\|^{2}\left(-1+\frac{1}{m}\right) .
\end{aligned}
$$

Theorem 3.6 Suppose that Assumption 1 holds. Consider the CG method of the form (1.2), (1.3), and (2.3), where $\alpha_{k}$ is computed by (1.5) and (1.6), then the iterates $\beta_{k}^{A 2}$ satisfy Property*.

Proof Let $\lambda=\frac{(1-\sigma) c \gamma^{2}}{2 L(L+1) \bar{\gamma} b}$ and

$$
\begin{aligned}
\beta_{k}^{A 2} & =\frac{\left\|g_{k}\right\|^{2}-\mu_{k}\left|g_{k}^{T} g_{k-1}\right|}{m\left|g_{k}^{T} d_{k-1}\right|+d_{k-1}^{T} y_{k-1}} \leq \frac{\left\|g_{k}\right\|^{2}-\mu_{k}\left|g_{k}^{T} g_{k-1}\right|}{d_{k-1}^{T} y_{k-1}} \\
& \leq \frac{\left\|g_{k}\right\|^{2}-\mu_{k}\left|g_{k}^{T} g_{k-1}\right|}{(1-\sigma) c\left\|g_{k-1}\right\|^{2}} \leq \frac{\left\|g_{k}\right\|^{2}+\left|g_{k}^{T} g_{k-1}\right|}{(1-\sigma) c\left\|g_{k-1}\right\|^{2}} \\
& \leq \frac{\left\|g_{k}\right\|\left(\left\|g_{k}\right\|+\left\|g_{k-1}\right\|\right)}{(1-\sigma) c\left\|g_{k-1}\right\|^{2}} \leq \frac{2 \bar{\gamma}^{2}}{(1-\sigma) c \gamma^{2}}=b>1 .
\end{aligned}
$$

To show that $\beta_{k}^{A 2} \leq \frac{1}{2 b}$, we have the following two cases: 
Case $\mu_{k}>1$

$$
\begin{aligned}
\beta_{k}^{A 2} & =\frac{\left\|g_{k}\right\|^{2}-\mu_{k}\left|g_{k}^{T} g_{k-1}\right|}{m\left|g_{k}^{T} d_{k-1}\right|+d_{k-1}^{T} y_{k-1}} \leq \frac{\left\|g_{k}\right\|^{2}-\left|g_{k}^{T} g_{k-1}\right|}{d_{k-1}^{T} y_{k-1}} \\
& \leq \frac{\left\|g_{k}\right\|\left\|g_{k}-g_{k-1}\right\|}{(1-\sigma) c\left\|g_{k-1}\right\|^{2}} \leq \frac{L \lambda \bar{\gamma}}{(1-\sigma) c \gamma^{2}} .
\end{aligned}
$$

Case $\mu_{k}<1$

To satisfy Property" for $\beta_{k}^{A 1}$ with $\mu_{k}<1$, we need property (3.3) which gives

$$
\begin{aligned}
\left|\beta_{k}^{A 2}\right| & \leq\left|\frac{\left\|g_{k}\right\|^{2}-\mu_{k}\left|g_{k}^{T} g_{k-1}\right|}{m\left|g_{k}^{T} d_{k-1}\right|+d_{k-1}^{T} y_{k-1}}\right| \\
& \leq\left|\frac{\left\|g_{k}\right\|^{2}-\frac{1}{L}\left|g_{k}^{T} g_{k-1}\right|}{d_{k-1}^{T} y_{k-1}}\right| \\
& \leq\left|\frac{\left\|g_{k}\right\|\left\|g_{k}-\frac{1}{L} g_{k-1}\right\|}{(1-\sigma) c\left\|g_{k-1}\right\|^{2}}\right| .
\end{aligned}
$$

Using (3.3), we obtain

$$
\begin{aligned}
& \left\|g_{k}-\frac{1}{L} g_{k-1}\right\| \leq L\left\|g_{k}-\frac{1}{L} g_{k-1}+\frac{1}{L} g_{k}-g_{k-1}\right\| \leq(L+1)\left\|g_{k}-g_{k-1}\right\|, \\
& \left|\beta_{k}^{A 2}\right| \leq \frac{(L+1)\left\|g_{k}\right\|\left\|g_{k}-g_{k-1}\right\|}{(1-\sigma) c\left\|g_{k-1}\right\|^{2}} \leq L \frac{(L+1) \lambda \bar{\gamma}}{(1-\sigma) c \gamma^{2}} .
\end{aligned}
$$

Thus, in all cases

$$
\left|\beta_{k}^{A 2}\right| \leq \frac{L \lambda \bar{\gamma}}{(1-\sigma) c \gamma^{2}} \leq L \frac{(L+1) \lambda \bar{\gamma}}{(1-\sigma) c \gamma^{2}} \leq \frac{1}{2 b} .
$$

Theorem 3.7 Suppose that Assumption 1 holds. Consider the CG method of the form (1.2), (1.3), and (2.3), i.e., $\beta_{k}^{A 2}$, where $\alpha_{k}$ is computed by (1.5) and (1.6), then $\lim _{k \rightarrow \infty}\left\|g_{k}\right\|=0$.

Proof We will apply Theorem 3.1. Note that the following properties hold for $\beta_{k}^{A 2}$ :

i. $\beta_{k}^{A 2}>0$.

ii. $\beta_{k}^{A 2}$ satisfies Property" by using Theorem 3.6.

iii. $\beta_{k}^{A 2}$ satisfies the descent property by using Theorem 3.5 .

iv. Assumption 1 holds.

Thus all properties in Theorem 3.1 are satisfied, which leads to $\lim _{k \rightarrow \infty}\left\|g_{k}\right\|=0$.

If the condition $\left\|g_{k}\right\|^{2}>\mu_{k}\left|g_{k}^{T} g_{k-1}\right|$ does not hold for $\beta_{k}^{A 1}$ and $\beta_{k}^{A 2}$, then the CG method will be restarted using $\beta_{k}^{D-H}=-\mu_{k} \frac{g_{k}^{T} s_{k-1}}{d_{k-1}^{T} y_{k-1}}$.

The following two theorems show that the CG method with $\beta_{k}^{D-H}$ has the descent and convergence properties.

Theorem 3.8 Let sequences $\left\{x_{k}\right\}$ and $\left\{d_{k}\right\}$ be obtained using Eqs. (1.2) and (1.3), which is computed by SWP line search in Eqs. (1.5) and (1.7), then the descent condition holds for $\left\{d_{k}\right\}$ with $\beta_{k}^{D-H}$. 
Proof By multiplying Eq. (1.3) with $g_{k}^{T}$, and substituting $\beta_{k}^{D-H}$, we obtain

$$
\begin{aligned}
g_{k}^{T} d_{k} & =-\left\|g_{k}\right\|^{2}-t \frac{g_{k}^{T} s_{k-1}}{d_{k}^{T} y_{k-1}} g_{k}^{T} d_{k-1} \\
& =-\left\|g_{k}\right\|^{2}-t \alpha_{k} \frac{\left\|g_{k}^{T} d_{k-1}^{T}\right\|^{2}}{d_{k}^{T} y_{k-1}} \leq-\left\|g_{k}\right\|^{2} .
\end{aligned}
$$

Letting $c=1$, we then obtain

$$
g_{k}^{T} d_{k} \leq-c\left\|g_{k}\right\|^{2}
$$

which completes the proof.

Theorem 3.9 Assume that Assumption 1 holds. Consider the conjugate gradient method in (1.2) and (1.3) with $\beta_{k}^{D-H}$ a descent direction and $\alpha_{k}$ obtained by the strong Wolfe line search. Then, $\liminf _{k \rightarrow \infty}\left\|g_{k}\right\|=0$.

Proof We will prove this theorem by contradiction. Suppose Theorem 3.4 is not true. Then, a constant $\varepsilon>0$ exists such that

$$
\left\|g_{k}\right\| \geq \varepsilon, \quad \forall k \geq 1
$$

By squaring both sides of (1.2), we obtain

$$
\begin{aligned}
\left\|d_{k}\right\|^{2} & =\left\|g_{k}\right\|^{2}-2 \beta_{k} g_{k}^{T} d_{k-1}+\beta_{k}^{2}\left\|d_{k-1}\right\|^{2} \\
& \leq\left\|g_{k}\right\|^{2}+2\left|\beta_{k}\right|\left|g_{k}^{T} d_{k-1}\right|+\beta_{k}^{2}\left\|d_{k-1}\right\|^{2} \\
& \leq\left\|g_{k}\right\|^{2}+\frac{2}{L} \frac{\left\|g_{k}\right\|\left\|s_{k}\right\|}{(1-\sigma)\left|g_{k-1}^{T} d_{k-1}\right|}(\sigma)\left|g_{k-1}^{T} d_{k-1}\right|+\frac{1}{L^{2}} \frac{\left((\sigma) g_{k-1}^{T} d_{k-1}\right)^{2}\left\|s_{k-1}\right\|^{2}}{\left((1-\sigma) g_{k-1}^{T} d_{k-1}\right)^{2}} \\
& \leq\left\|g_{k}\right\|^{2}+\frac{2}{L} \frac{\left\|g_{k}\right\|\left\|s_{k}\right\|}{(1-\sigma)} \sigma+\frac{1}{L^{2}} \frac{(\sigma)^{2}\left\|s_{k-1}\right\|^{2}}{(1-\sigma)^{2}}, \\
\frac{\left\|d_{k}\right\|^{2}}{\left\|g_{k}\right\|^{4}} & \leq \frac{\left\|g_{k}\right\|^{2}}{\left\|g_{k}\right\|^{4}}+\frac{2}{L} \frac{\left\|g_{k}\right\|\left\|s_{k}\right\|}{(1-\sigma)\left\|g_{k}\right\|^{4}} \sigma+\frac{1}{L^{2}} \frac{\sigma^{2}\left\|s_{k-1}\right\|^{2}}{(1-\sigma)^{2}\left\|g_{k}\right\|^{4}} \\
& \leq \frac{1}{\left\|g_{k}\right\|^{2}}+\frac{2}{L} \frac{\left\|g_{k}\right\|\left\|s_{k}\right\|}{(1-\sigma)\left\|g_{k}\right\|^{4}} \sigma+\frac{1}{L^{2}} \frac{\sigma^{2}\left\|s_{k-1}\right\|^{2}}{(1-\sigma)^{2}\left\|g_{k}\right\|^{4}} \\
& \leq \frac{1}{\left\|g_{k}\right\|^{2}}+\frac{2}{L} \frac{\left\|s_{k}\right\|}{(1-\sigma)\left\|g_{k}\right\|^{3}} \sigma+\frac{1}{L^{2}} \frac{\sigma^{2}\left\|s_{k-1}\right\|^{2}}{(1-\sigma)^{2}\left\|g_{k}\right\|^{4}} .
\end{aligned}
$$

Let

$$
\left\|g_{k}\right\|^{q}=\min \left\{\left\|g_{k}\right\|^{2},\left\|g_{k}\right\|^{3},\left\|g_{k}\right\|^{4}\right\}, \quad q \in N,
$$

then

$$
\frac{\left\|d_{k}\right\|^{2}}{\left\|g_{k}\right\|^{4}} \leq \frac{1}{\left\|g_{k}\right\|^{q}}\left(1+\frac{2}{L} \frac{\lambda}{(1-\sigma)} \sigma+\frac{1}{\lambda^{2}} \frac{\sigma^{2} \lambda^{2}}{(1-\sigma)^{2}}\right) .
$$


Also, let

$$
R=\left(1+\frac{2}{L} \frac{\lambda}{(1-\sigma)} \sigma+\frac{1}{\lambda^{2}} \frac{\sigma^{2} \lambda^{2}}{(1-\sigma)^{2}}\right)
$$

then

$$
\begin{aligned}
& \frac{\left\|d_{k}\right\|^{2}}{\left\|g_{k}\right\|^{4}} \leq \frac{R}{\left\|g_{k}\right\|^{q}} \leq R \sum_{i=1}^{k} \frac{1}{\left\|g_{i}\right\|^{q}}, \\
& \frac{\left\|g_{k}\right\|^{4}}{\left\|d_{k}\right\|^{2}} \geq \frac{\varepsilon^{q}}{k R} .
\end{aligned}
$$

Therefore,

$$
\sum_{k=0}^{\infty} \frac{\left\|g_{k}\right\|^{4}}{\left\|d_{k}\right\|^{2}}=\infty
$$

\section{Numerical results and discussions}

To analyze the efficiency of the new CG method, several test functions are selected from CUTE [20], as shown in the Appendix. These functions can be obtained from the following website:

http://ccpforge.cse.rl.ac.uk/gf/project/cutest/wiki/

In the Appendix, the following notations are defined as follows:

- No. iter means the number of iterations.

- No. fun. Eva means the number of function evaluations.

- No. Grad. Eva means the number of gradient evaluations.

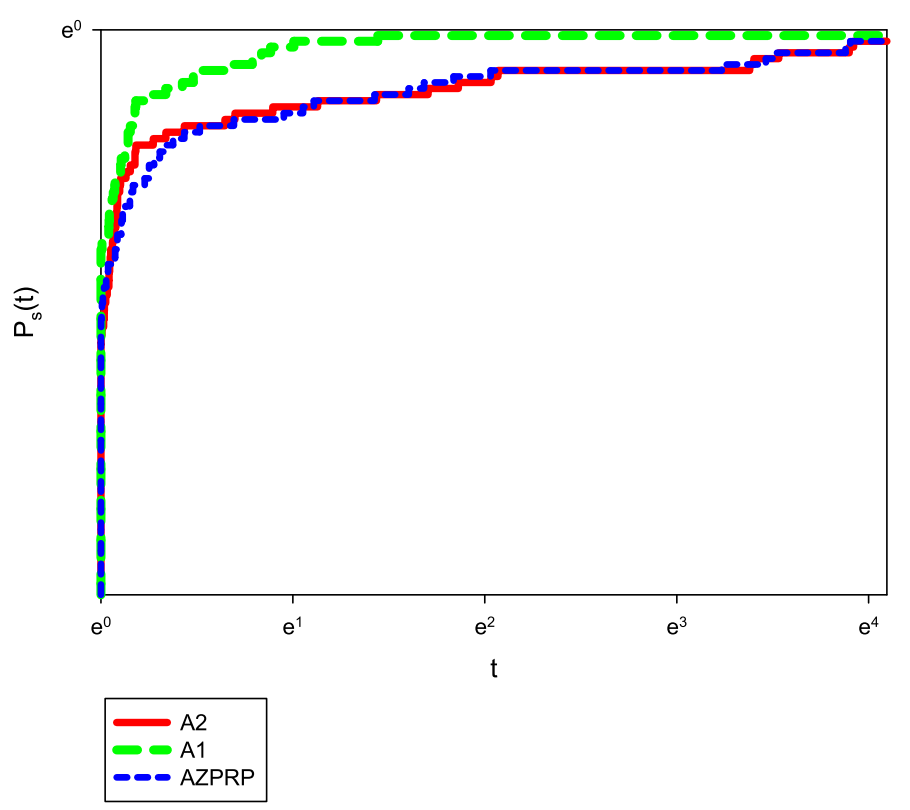

Figure 4 Performance profile based on the number of iteration 


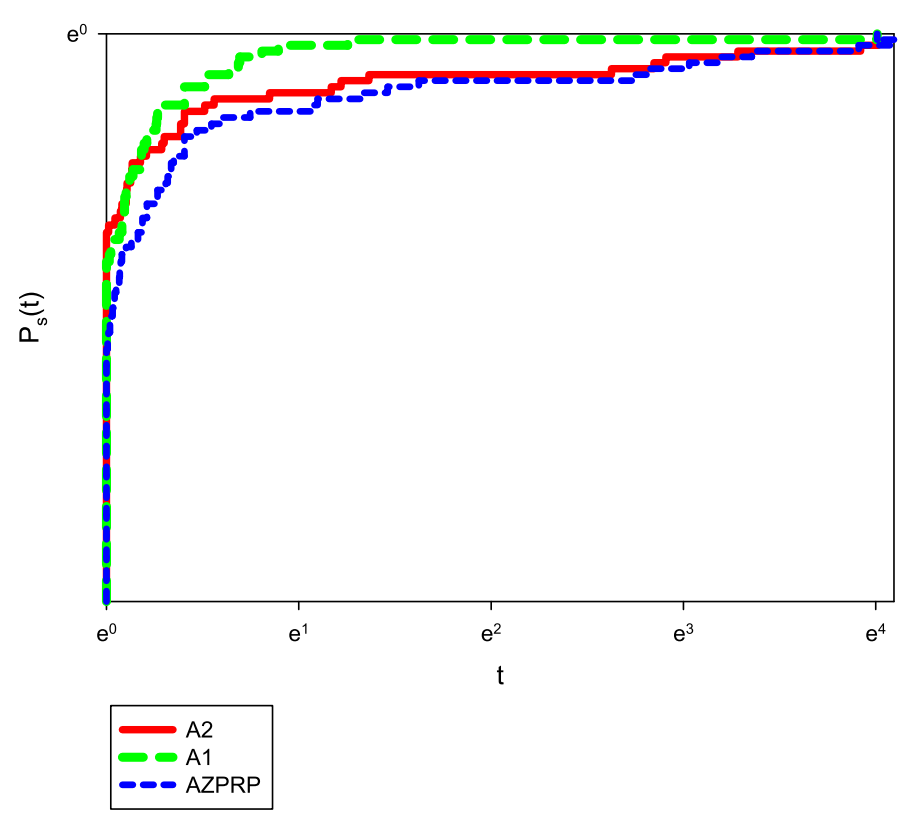

Figure 5 Performance profile based on the CPU time

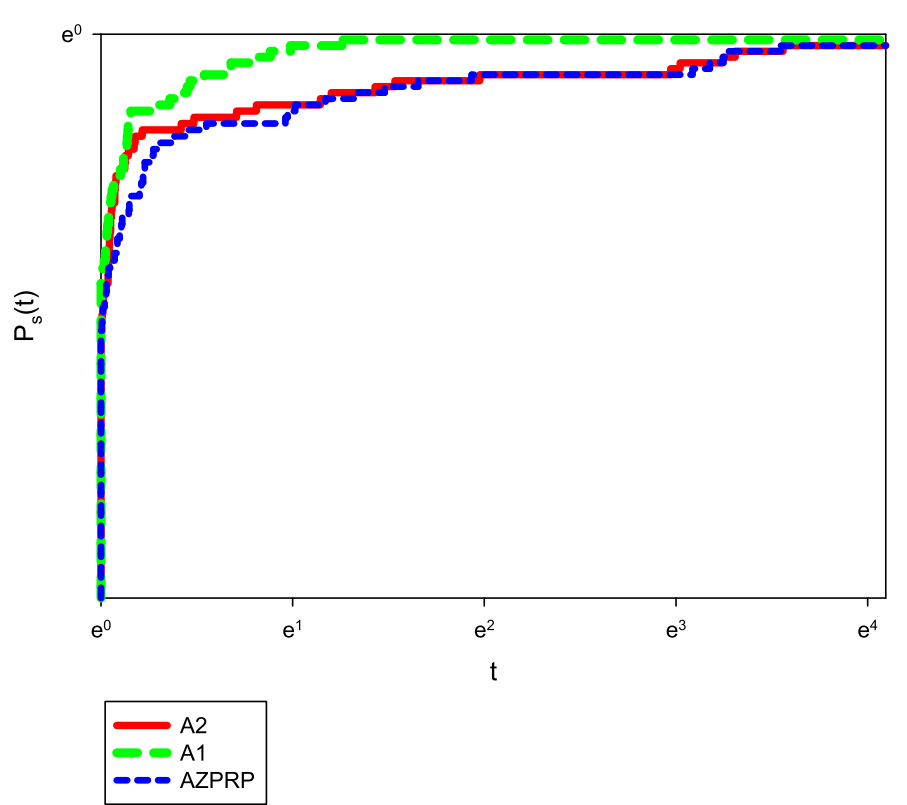

Figure 6 Performance profile based on the functions evaluation time

The comparison was made with respect to CPU time, the number of function evaluations, the number of iterations, and the number of gradient evaluations. The SWP line search is employed with the following parameters of $\delta=0.01$ and $\sigma=0.1$. The modified CG-Descent 6.8 with zero memory is employed to obtain the result for $\beta_{k}^{A 1}, \beta_{k}^{A 2}$. The code can be downloaded from the Hager webpage:

http://users.clas.ufl.edu/hager/papers/Software/ 


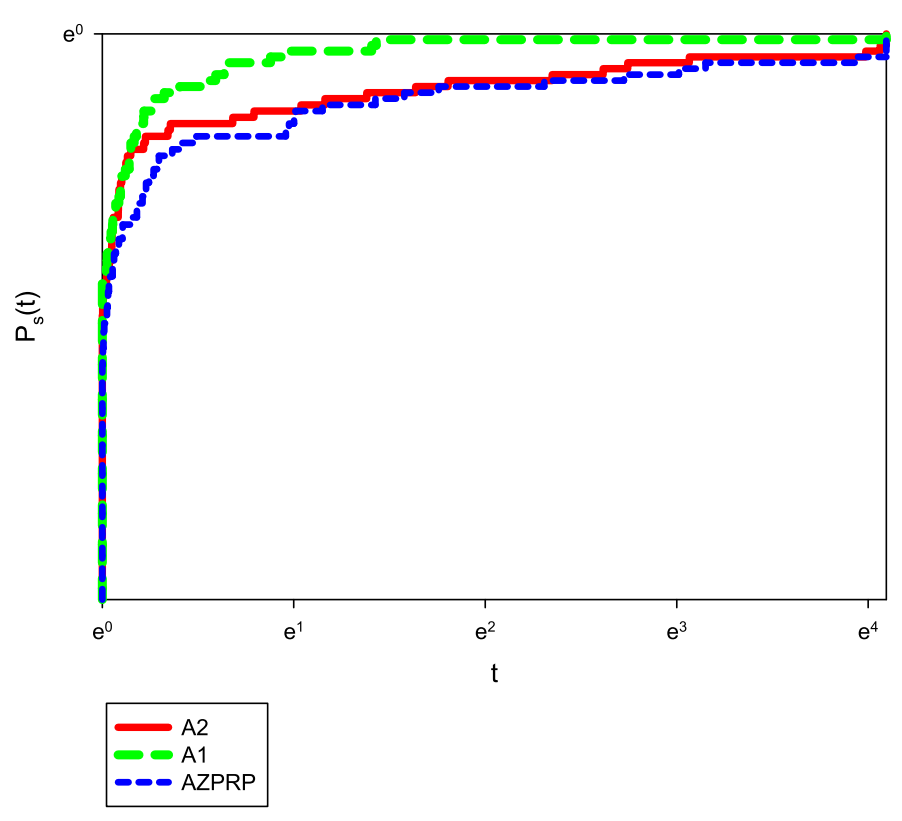

Figure 7 Performance profile based on the gradient evaluations

A minimum time of 0.02 seconds is used for all algorithms. The host computer is an Intel ${ }^{\circ}$ Dual-Core CPU with 2 GB of DDR2 RAM. The results are shown in Figs. 4, 5, 6, and 7, in which a performance measure introduced by Dolan and Moré [21] was employed.

It is clear that based on the left-hand side of Figs. 4, 5, 6, and 7, the CG method A1 is above the other curves. Therefore, it is the most efficient method among related AZPRP methods. However, CG method A2 is not as efficient as A1. Still, it is more efficient than AZPRP with respect to CPU time, the number of function evaluations, gradient evaluations, and the number of iterations. In addition, as an application of the CG method in image restoration, the reader can refer to the following references [22-24].

\section{Conclusion}

In this paper, we proposed two efficient conjugate gradient methods related to the AZPRP method. The two methods satisfied global convergence properties and the descent property when SWP line searches were employed. Furthermore, our numerical results showed that the new methods are more efficient than the AZPRP method with respect to the number of iterations, gradient evaluations, function evaluations, and CPU time. 


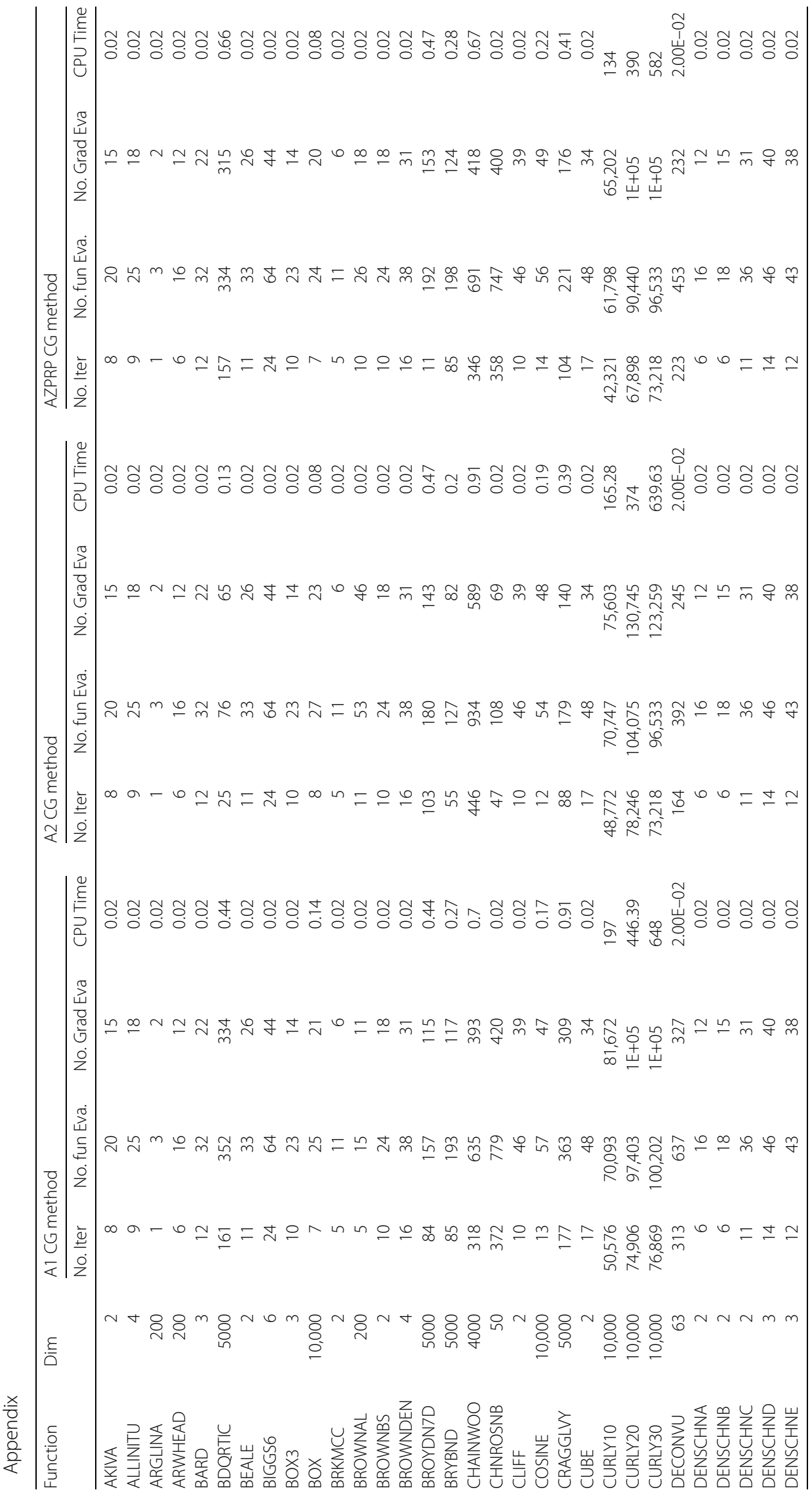




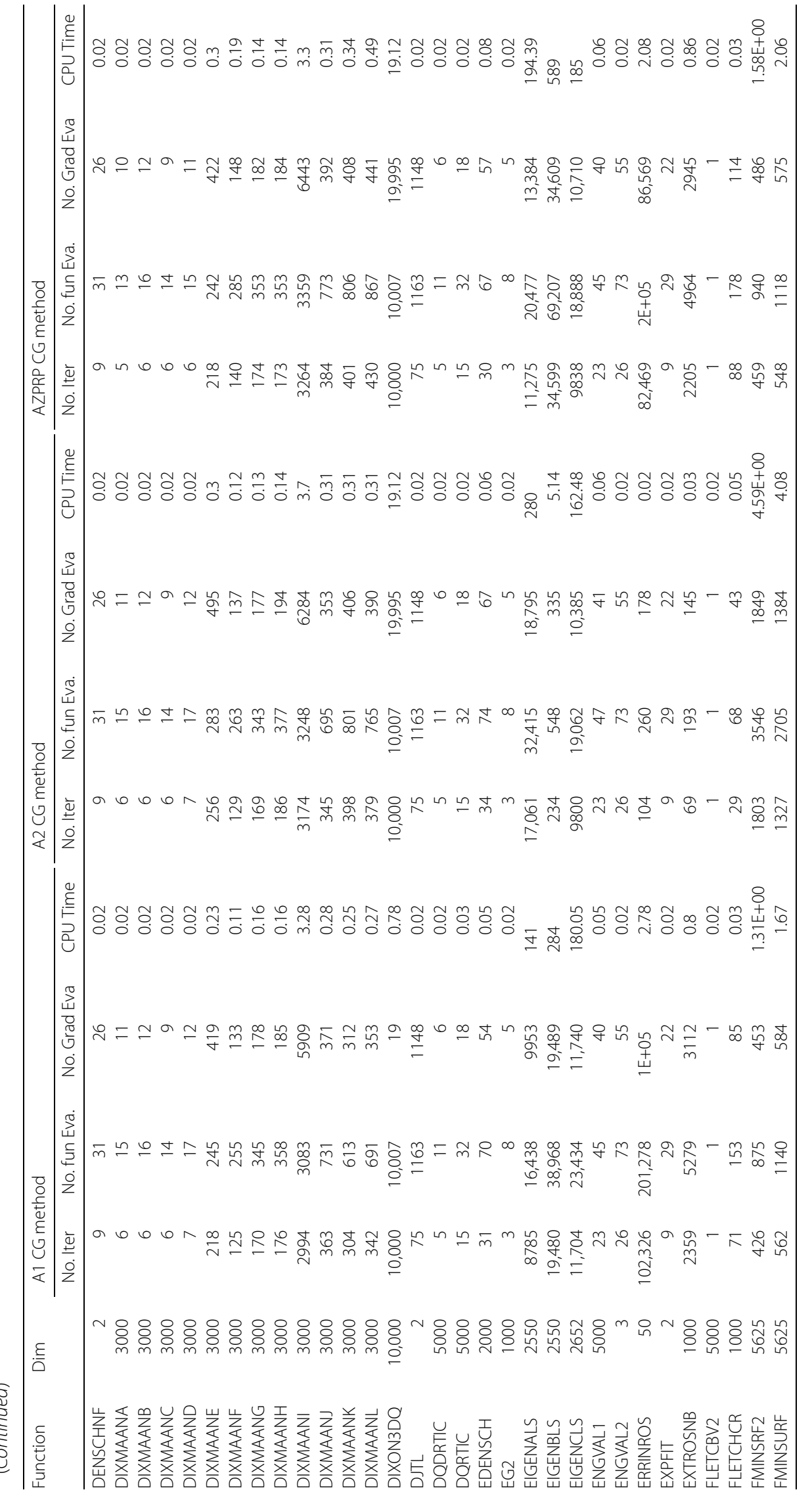




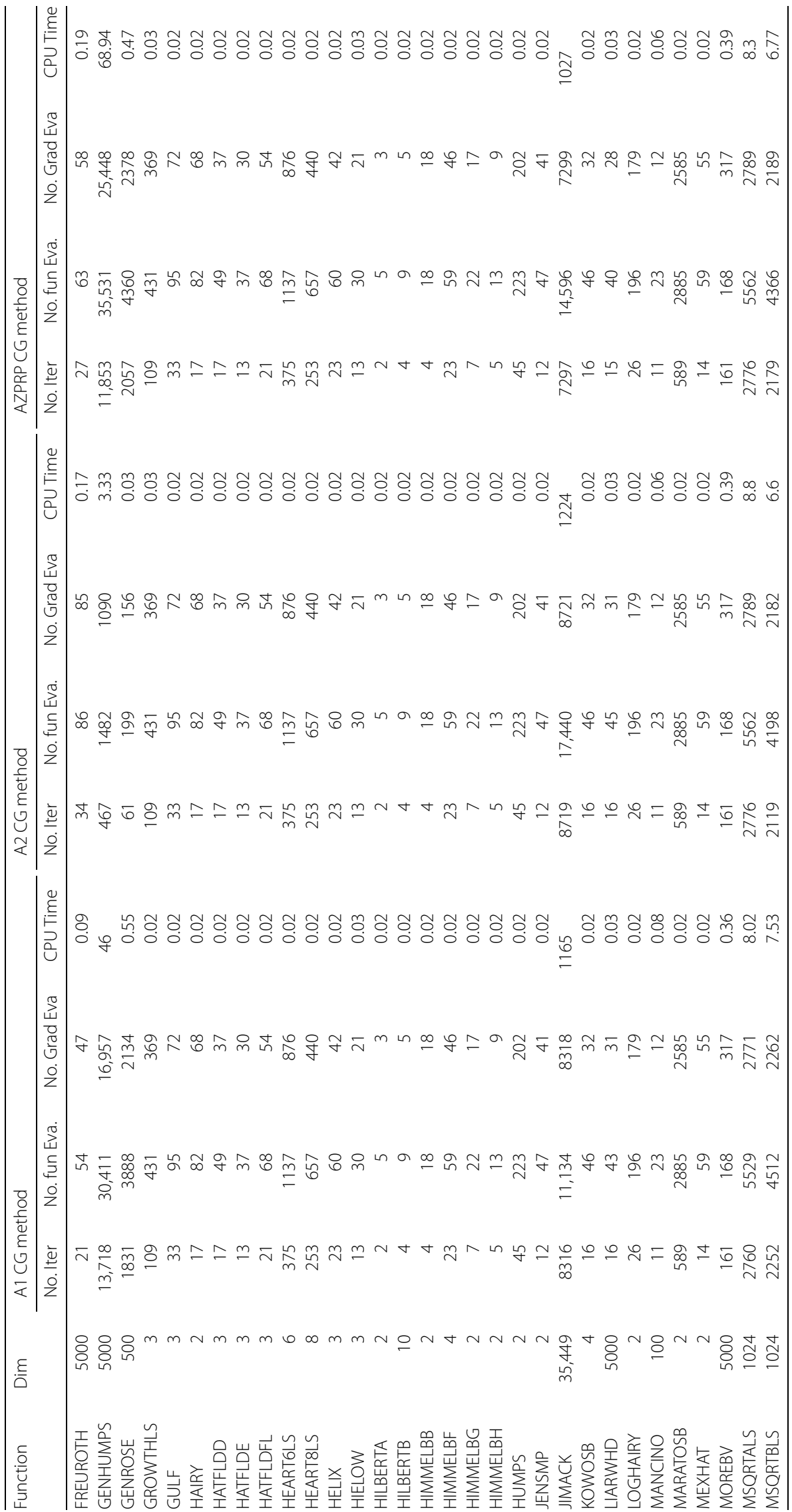




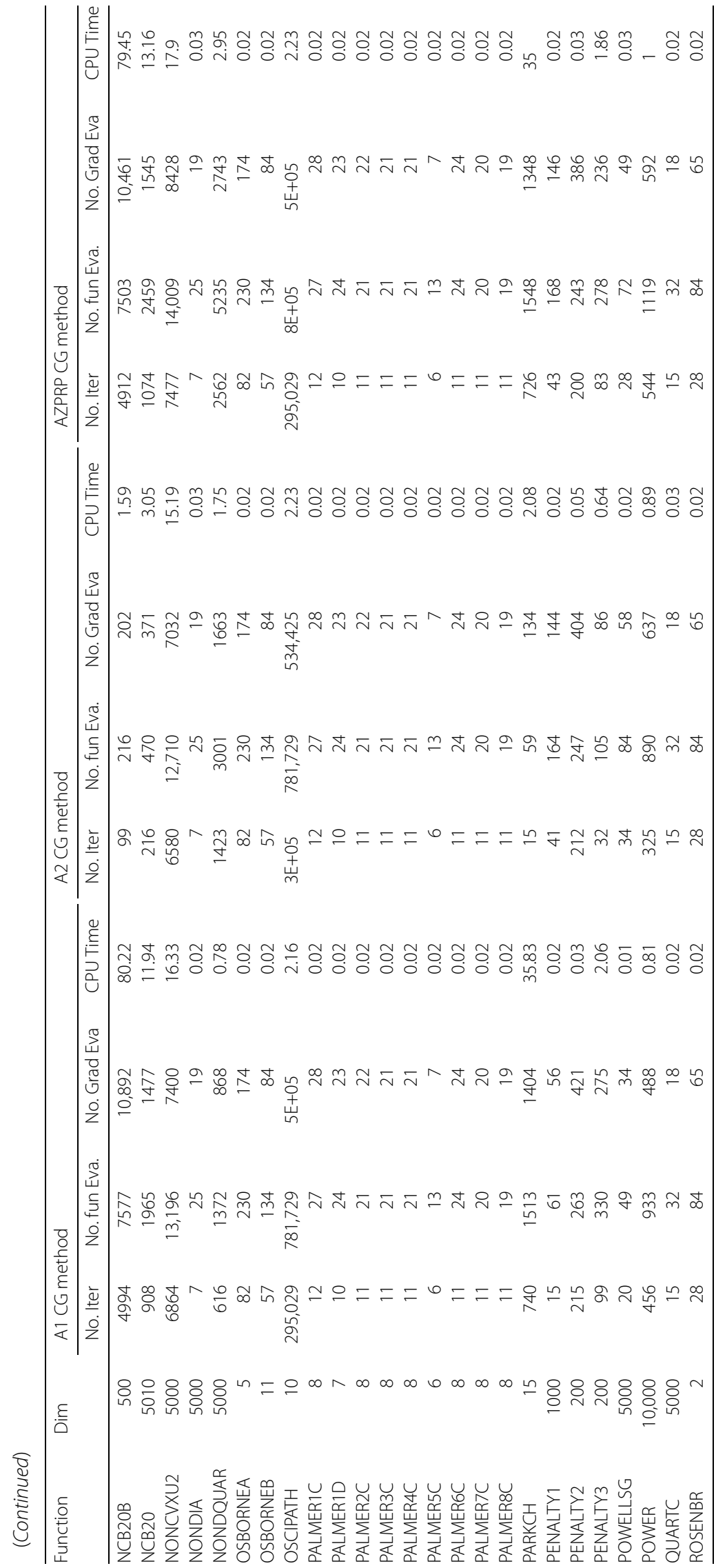




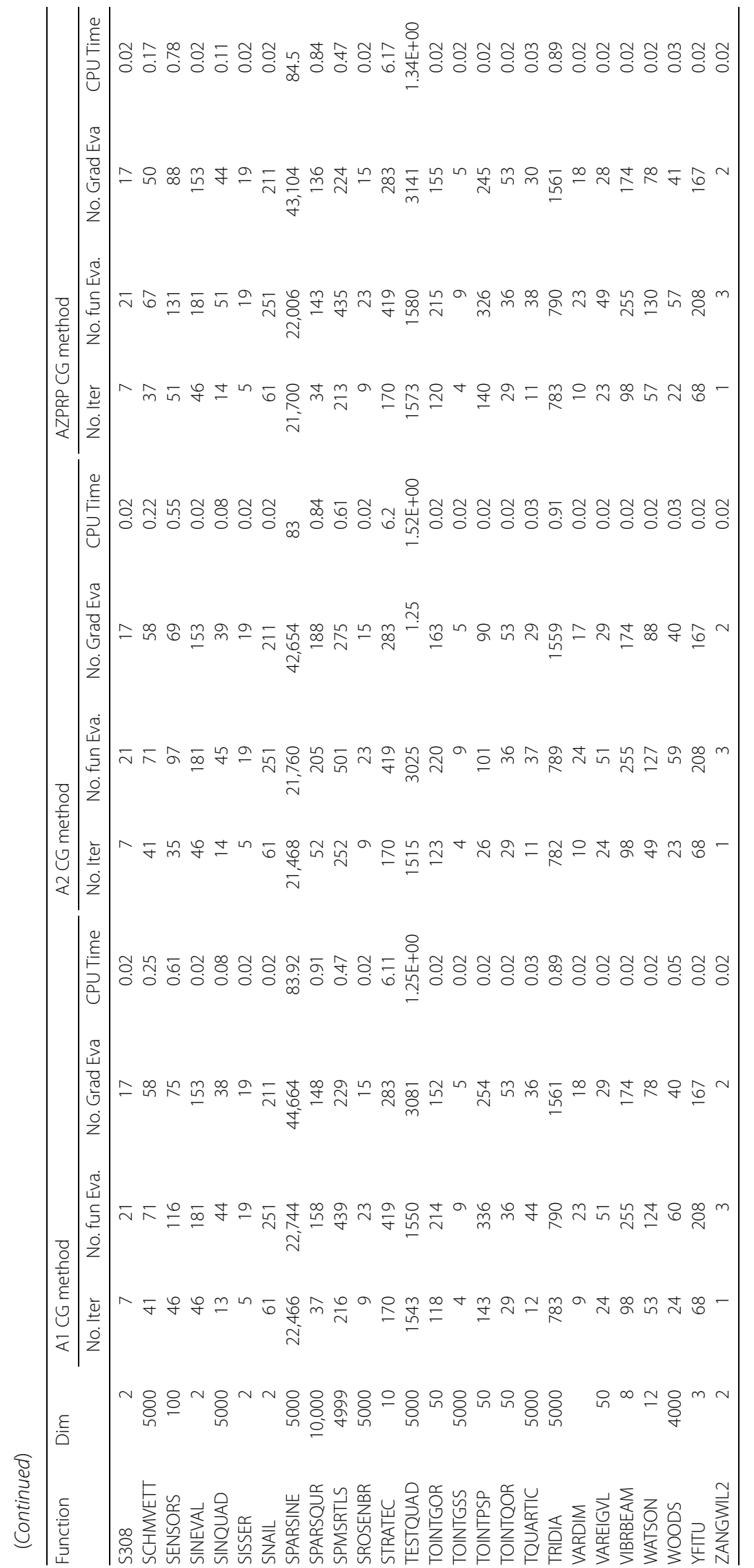




\section{Acknowledgements}

The authors are grateful for all this support and improve our paper; also, we would like to thank the University of Malaysia Terengganu (UMT) for funding this paper.

Funding

This study was partially supported by the Universiti Malaysia Terengganu, Centre of Research and Innovation Management.

\section{Availability of data and materials}

The data is available inside the paper.

\section{Declarations}

\section{Competing interests}

The authors declare that they have no competing interests.

\section{Authors' contributions}

The authors contributed equally and significantly in writing this paper. All authors read and approved the final manuscript.

\section{Author details}

1 Department of Mathematics, Faculty of Ocean Engineering Technology and Informatics, Universiti Malaysia Terengganu, 21030 Kuala Nerus, Terengganu, Malaysia. ${ }^{2}$ Department of Mathematics, Faculty of Science, Jazan University, Jazan, Saudi Arabia.

\section{Publisher's Note}

Springer Nature remains neutral with regard to jurisdictional claims in published maps and institutional affiliations.

Received: 17 March 2021 Accepted: 22 December 2021 Published online: 10 January 2022

\section{References}

1. Wolfe, P.: Convergence conditions for ascent methods. SIAM Rev. 11(2), 226-235 (1969)

2. Wolfe, P.: Convergence conditions for ascent methods. II: some corrections. SIAM Rev. 13(2), 185-188 (1971)

3. Hestenes, M.R., Stiefel, E.: Methods of conjugate gradients for solving linear systems. J. Res. Natl. Bur. Stand. 49(6), 409-436 (1952)

4. Polak, E., Ribiere, G.: Note sur la convergence de méthodes de directions conjuguées. ESAIM: Math. Model. Numer. Anal. 3(R1), 35-43 (1969)

5. Liu, Y., Storey, C.: Efficient generalised conjugate gradient algorithms, part 1: theory. J. Optim. Theory Appl. 69(1), 129-137 (1991)

6. Fletcher, R., Reeves, C.M.: Function minimisation by conjugate gradients. Comput. J. 7(2), 149-154 (1964)

7. Fletcher, R.: Practical Method of Optimisation. Unconstrained Optimisation, edn. (1997)

8. Dai, Y.H., Yuan, Y.: A non-linear conjugate gradient method with a strong global convergence property. SIAM J. Optim. 10(1), 177-182 (1999)

9. Zoutendijk, G.: Non-linear programming, computational methods. In: Integer and Non-linear Programming, pp. 37-86 (1970)

10. Al-Baali, M.: Descent property and global convergence of the Fletcher-Reeves method with inexact line search. IMA J. Numer. Anal. 5(1), 121-124 (1985)

11. Powell, M.J.: Non-convex minimisation calculations and the conjugate gradient method. In: Numerical Analysis, pp. 122-141. Springer, Berlin (1984)

12. Gilbert, J.C., Nocedal, J.: Global convergence properties of conjugate gradient methods for optimisation. SIAM J. Optim. 2(1), 21-42 (1992)

13. Dai, Y.H., Liao, L.Z.: New conjugacy conditions and related non-linear conjugate gradient methods. Appl. Math. Optim. 43(1), 87-101 (2001)

14. Hager, W.W., Zhang, H.: A new conjugate gradient method with guaranteed descent and an efficient line search. SIAM J. Optim. 16(1), 170-192 (2005)

15. Hager, W.W., Zhang, H.: The limited memory conjugate gradient method. SIAM J. Optim. 23(4), $2150-2168$ (2013)

16. Wei, Z., Yao, S., Liu, L.: The convergence properties of some new conjugate gradient methods. Appl. Math. Comput. 183(2), 1341-1350 (2006)

17. Dai, Z., Wen, F.: Another improved Wei-Yao-Liu non-linear conjugate gradient method with sufficient descent property. Appl. Math. Comput. 218(14), 7421-7430 (2012)

18. Alhawarat, A., Salleh, Z., Mamat, M., Rivaie, M.: An efficient modified Polak-Ribière-Polyak conjugate gradient method with global convergence properties. Optim. Methods Softw. 32(6), 1299-1312 (2017)

19. Kaelo, P., Mtagulwa, P., Thuto, M.V.: A globally convergent hybrid conjugate gradient method with strong Wolfe conditions for unconstrained optimisation. Math. Sci. 14(1), 1-9 (2020)

20. Bongartz, I., Conn, A.R., Gould, N., Toint, P.L.: CUTE: constrained and unconstrained testing environment. ACM Trans. Math. Softw. 21(1), 123-160 (1995)

21. Dolan, E.D., Moré, J.J.: Benchmarking optimisation software with performance profiles. Math. Program. 91(2), 201-213 (2002)

22. Alhawarat, A., Salleh, Z., Masmali, I.A.: A convex combination between two different search directions of conjugate gradient method and application in image restoration. Math. Probl. Eng. 2021, Article ID 9941757 (2021).

https://doi.org/10.1155/2021/9941757 
23. Guessab, A., Driouch, A.: A globally convergent modified multivariate version of the method of moving asymptotes. Appl. Anal. Discrete Math. 15(2), 519-535 (2021)

24. Guessab, A., Driouch, A., Nouisser, O.: A globally convergent modified version of the method of moving asymptotes. Appl. Anal. Discrete Math. 13(3), 905-917 (2019)

Submit your manuscript to a SpringerOpen ${ }^{\circ}$ journal and benefit from:

- Convenient online submission

- Rigorous peer review

- Open access: articles freely available online

- High visibility within the field

- Retaining the copyright to your article

Submit your next manuscript at $\boldsymbol{~ s p r i n g e r o p e n . c o m ~}$ 